\title{
Case report: Atypical presentation of giant cell tumour (GCT) of bone in the distal humerus of a child
}

\author{
M Tomlinson MBBCh \\ GJ Kubicek MD, MRCS aff. (London, UK) \\ N Ferreira BSc, MBChB, FC Orth(SA), MMed(Orth, PhD \\ LC Marais MBChB, FCS Orth(SA), MMed(Ortho), PhD
}

Tumour Sepsis and Reconstruction Unit, Department of Orthopaedic Surgery, Grey's Hospital, Nelson R. Mandela

School of Medicine, University of KwaZulu-Natal

\author{
Corresponding author: \\ Dr Nando Ferreira \\ Department of Orthopaedic Surgery \\ Grey's Hospital \\ 3201 Pietermaritzburg \\ KwaZulu-Natal \\ South Africa \\ Tel: +27338973000 \\ Email: Nando.Ferreira@kznhealth.gov.za
}

\begin{abstract}
Introduction: Giant cell tumour of bone is a rare entity in children and seldom involves the distal humerus, even in adult patients. We present a case of giant cell tumour in the distal humerus of a child.

Case report: A 12-year-old boy presented to our tertiary level tumour unit with progressive pain in his left elbow and was radiologically and histologically found to have a giant cell tumour of his left distal humerus. He was treated with extended curettage, cryotherapy and PMMA cement with the addition of a supportive posteromedial locking plate. There was no recurrence noted at one-year follow-up.

Discussion: The literature is reviewed to determine the epidemiology of this tumour, the histological and radiological findings unique to the lesion and the current best practice of treatment.

Conclusion: A rare case of giant cell tumour in the distal humerus of a child is presented. Giant cell tumour of bone should be considered in the differential diagnosis of a lytic metaphyseal lesion if the growth plates are open.
\end{abstract}

Key words: giant cell tumour of bone, skeletally immature, distal humerus

http:/ / dx.doi.org/10.17159/2309-8309/2016/v15n1a2

\section{Introduction}

Giant cell tumour (GCT) is a primary benign bone tumour that is locally aggressive, rarely metastasises and seldom undergoes malignant transformation. It is diagnosed with combined radiological and histological assessment. GCT is infrequently seen before the closure of skeletal growth plates. When they occur in children, these lesions are generally localised in the metaphysis, as compared to adults where GCTs usually occur in the epiphysis. The ends of long, tubular bones are chiefly affected with the distal femur, proximal tibia and distal radius most commonly involved.

We present an especially unusual case of GCT that occurred in both a rare location (the distal humerus) and in a skeletally immature patient.

\section{Case report}

A 12-year-old male child was referred to our tertiary level tumour unit with a three-month history of progressive pain and swelling of the left elbow. The child was otherwise well, reporting no history of trauma to the elbow nor any constitutional symptoms.

The patient was admitted for local and systemic staging, which was followed by an incisional biopsy. Local staging included radiographs and a magnetic resonance imaging (MRI) scan. The radiographs showed a locally aggressive, geographic lytic lesion eccentrically located in the distal humeral metaphysis. The lesion had expanded the cortex, permeated through the bony confines, extended into the surrounding soft tissues, and no periosteal reaction was noted. According to 
Campanacci radiographic staging system this lesion was classified as a grade III GCT $^{1}$ (Figure 1). MRI scans revealed a large heterogeneous T2 hyperintense, T1 hypointense lesion (Figures 2 and 3). Systemic staging confirmed that the patient was generally well with no co-morbidities and a normal nutritional status. Computerised tomography (CT) scan of the chest and abdomen did not identify any metastatic lesions and a skeletal survey confirmed a single lesion located in the left distal humerus.

An incisional biopsy was performed through a posteromedial approach. The histological evaluation described a GCT with no malignant features and confirmed the classic findings of mononuclear cells with interspersed fibro-collagenous strands and numerous multinucleated osteoclast-like giant cells (Figure 4).

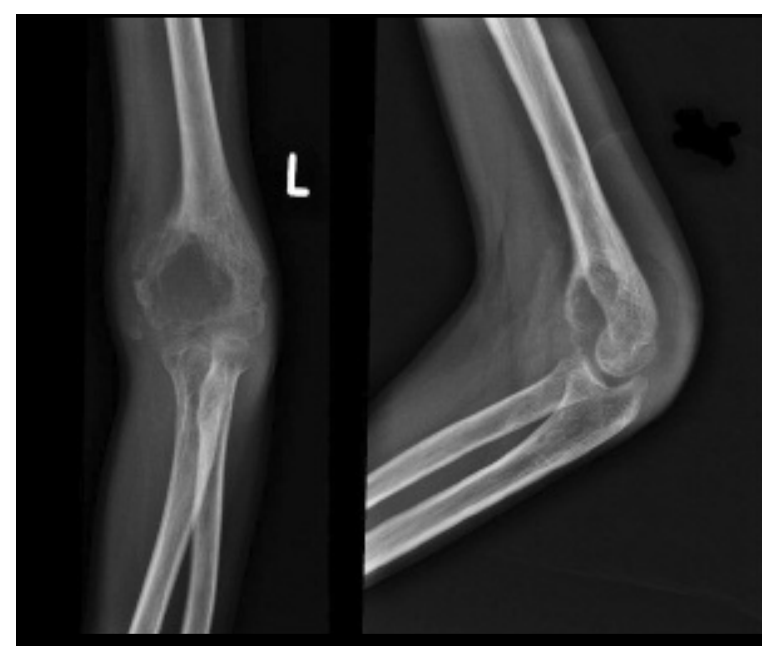

Figure 1. AP and lateral radiographs showing a large geographic lytic lesion of the left distal humerus with cortical expansion and destruction and extension into the physis and epiphysis
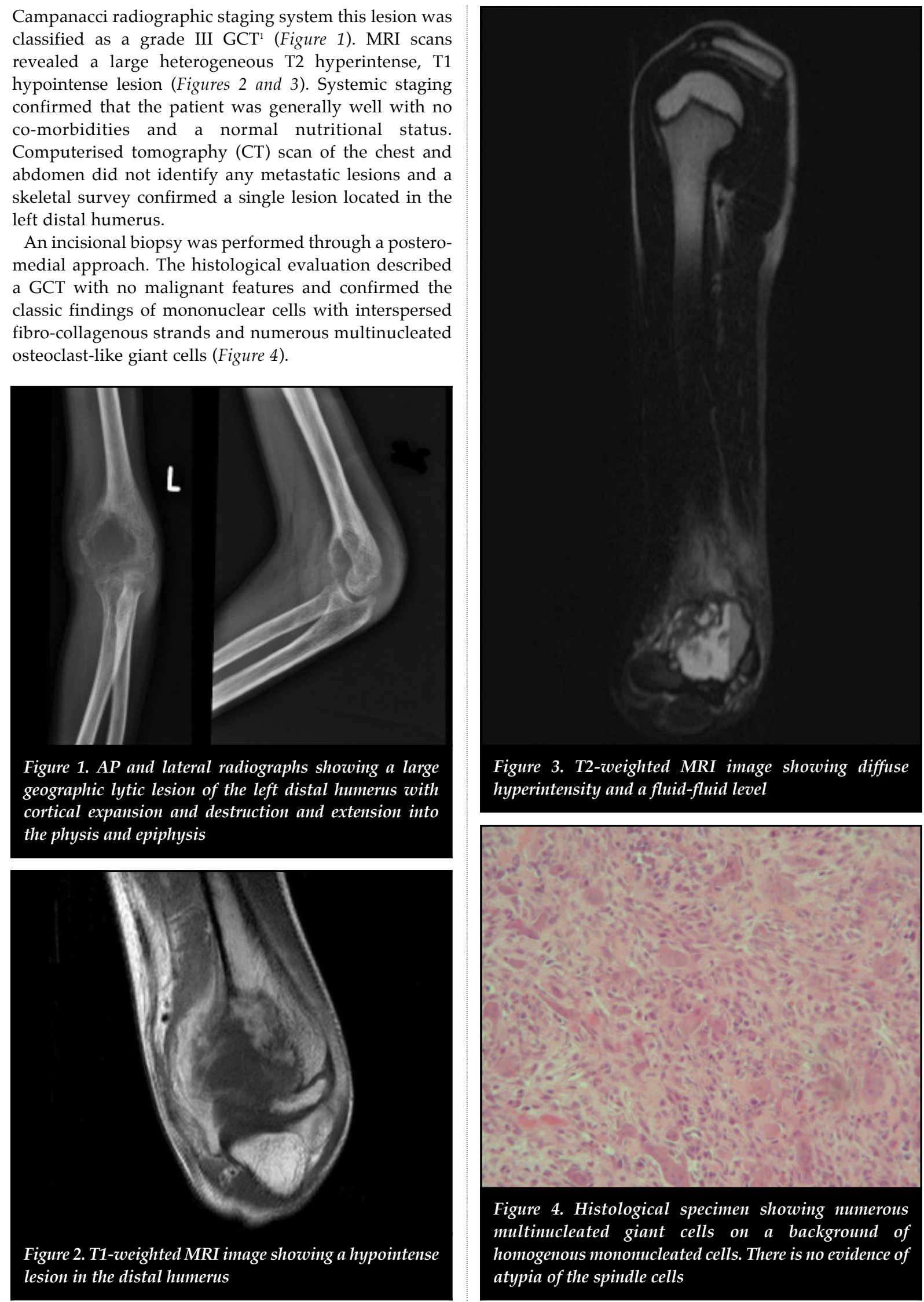

Figure 4. Histological specimen showing numerous multinucleated giant cells on a background of homogenous mononucleated cells. There is no evidence of atypia of the spindle cells 

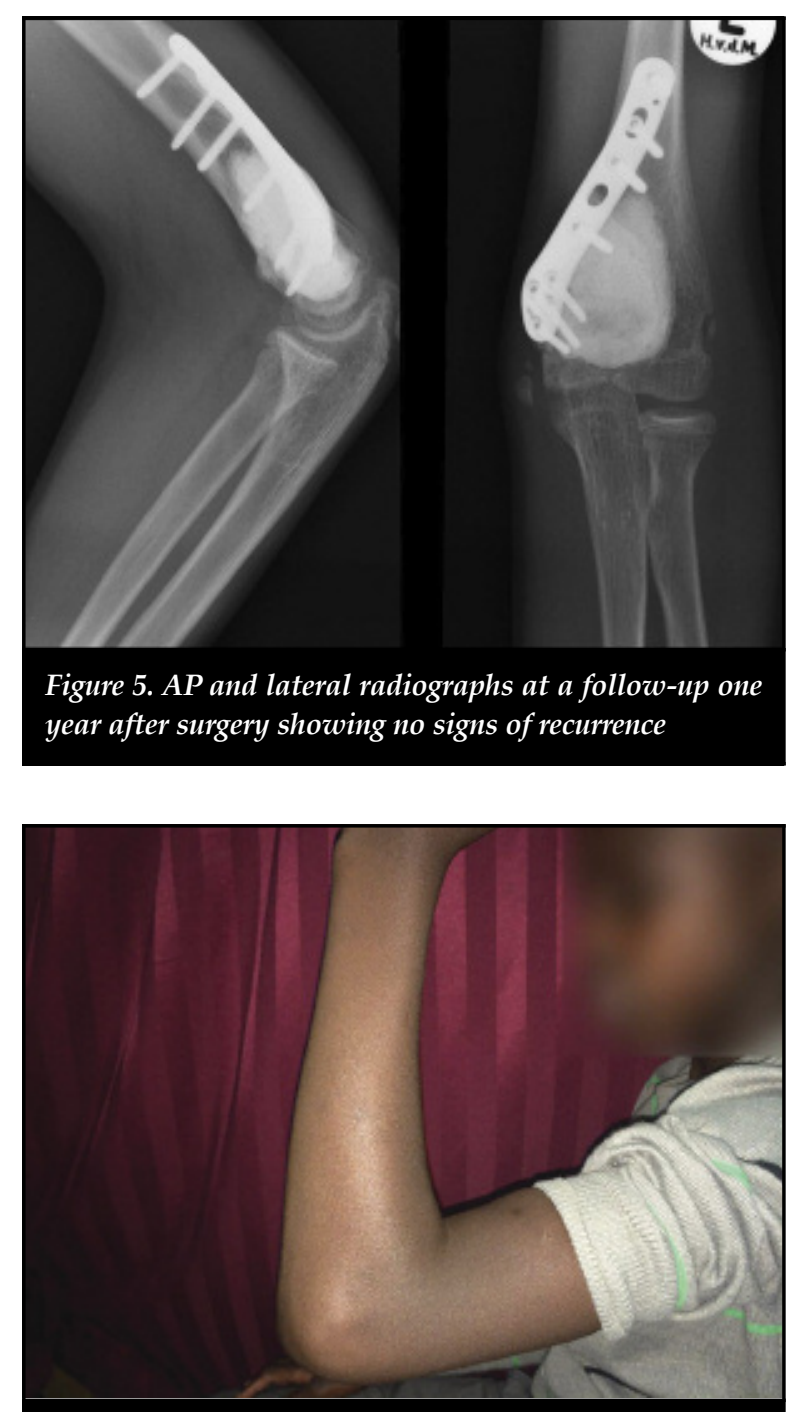

Figure 6

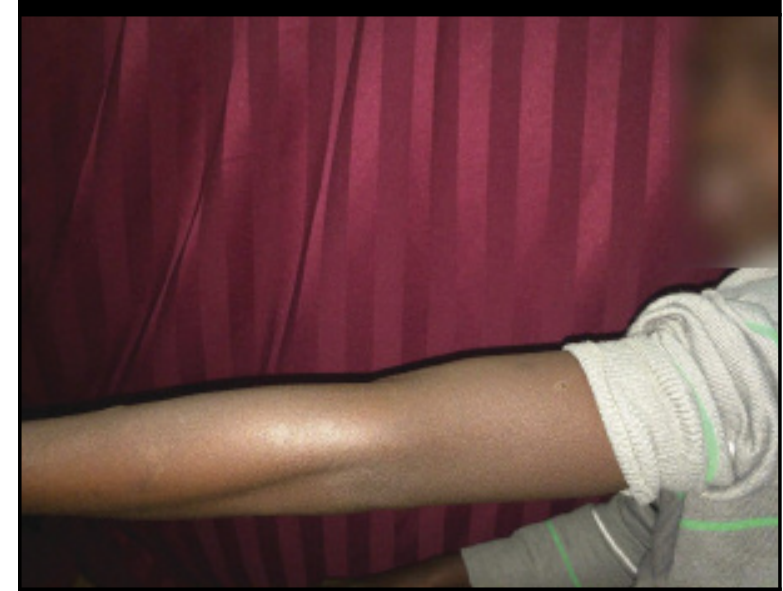

Figure 7

Figure 6 and 7. Elbow range of motion of $0^{\circ}-110^{\circ}$, one year after surgery
Definitive surgery was performed seven days after the histological confirmation was obtained. This was performed through a postero-medial approach based on the biopsy incision and consisted of curettage, extended with high-speed burring, and adjuvant cryotherapy with liquid nitrogen. The resultant cavity was filled with PMMA cement and supplemented with a postero-medial locking plate for stability (Figure 5). Confirmatory histology from the definitive procedure confirmed the incisional biopsy results of a benign GCT. At one-year follow-up the patient reported no pain, and a $0^{\circ}-110^{\circ}$ range of motion of the elbow. There were no clinical or radiological signs of recurrence (Figures 6 and 7).

\section{Discussion}

The World Health Organisation (WHO) classifies giant cell tumour of bone as a locally aggressive, potentially malignant lesion that can rarely produce metastases. ${ }^{2}$ The tumours generally develop slowly, metastasise in $1-3 \%$ of cases and do so most commonly to the lungs. ${ }^{3}$ Recurrence rates of between $0 \%$ and $63 \%$ have been published and depend largely on the type of treatment. ${ }^{4}$ Malignant transformation occurs in $5-10 \%$ of cases and most commonly follows radiation therapy of the primary lesion. ${ }^{5}$ Primary malignant GCT is a rare entity where synchronous coexistence of a sarcoma and benign GCT is found in the same lesion. ${ }^{2,6,7}$ Multicentric tumours are rare $(<1 \%)$ and are associated with a more aggressive course. $^{8}$

These lesions are classically described in individuals between the ages of 20-40 years with a slight female predominance and are rare in children before the closure of growth plates. ${ }^{2,69}$ The incidence in children younger than 19 years has been reported in several studies and ranges from $1.7 \%$ to as high as $10.6 \%$ of all patients with GCTs. ${ }^{10-15}$ GCTs are typically located in the epiphyseal region of long bones with the proximal tibia, distal femur and distal radius being the most commonly affected. ${ }^{2}$ In children there seems to be a relationship between age and proximity to the epiphysis. In young children the tumours are generally further from the epiphysis and more metaphyseally located..$^{10,12,15}$

Involvement of the humerus comprises approximately $6 \%$ of all GCTs, but almost all of these are located in the proximal humerus with distal humeral lesion being exceedingly rare. ${ }^{16}$ The current case demonstrates a rare occurrence of a GCT in the distal humerus of a child. At present only a single occurrence of distal humerus GCT has ever been reported in a child. This case, however, involved multicentric disease with foci also reported in the hand. ${ }^{17}$

GCT of bone is diagnosed histologically by the characteristic appearance of a heterogeneous group of cells containing most notably mononucleated plump spindle- or ovoid-shaped cells and osteoclast-like multinucleated giant cells. The histology found in this case represents a Jaffe grade I lesion. 
Although Jaffe's grading system was developed in order to predict patient outcomes, by his own admission, he was unable to correlate the histological findings with the probability of the lesion undergoing malignant transformation, the incidence of metastases or the frequency of recurrence., ${ }^{2,18}$

Typical radiographic findings include lytic lesions located eccentrically in the epiphysis that do not penetrate the joint. The rim of the lesion is generally not sclerotic and can extend into the surrounding tissue, which indicates a poorer prognosis. Differential diagnoses based on radiological findings include aneurysmal bone cyst, non-ossifying fibroma, primary hyperparathryroidism with brown tumours, chondromyxoid fibroma, chondroblastoma, clear cell chondrosarcoma and telangiectatic osteosarcoma. Researchers using MRI have found haemosiderin deposits in up to $60 \%$ of cases and although these findings are neither sensitive nor specific, it may be a useful adjunct in determining a diagnosis. ${ }^{19}$

Surgical treatment usually consists of extended curettage or en-bloc resection. Current evidence indicates that curettage should be supplemented with a combination of chemical cautery, cryotherapy or electrical cautery followed by methylmethacrylate cement to limit recurrence..$^{20,21}$ In the instance of this case a combination of curettage, burring and cryotherapy was used, after which cement was inserted in the cavity. The distal humerus was then stabilised with a postero-medial plate. At the one-year follow-up the patient, had no clinical or radiographic signs of recurrence. We continue to follow him up, as a minimum of three years' follow-up is suggested in GCT as most recurrence is seen within this period. ${ }^{20}$

\section{Conclusion}

This case report describes a rare occurrence of a GCT in the distal humerus of a child, and includes the diagnostic and treatment algorithms. Giant cell tumours have a variable presentation and should form part of a differential diagnosis of lytic metaphyseal bone lesions in children.

\section{Consent}

Written consent was obtained from the patient for publication of this case report and any accompanying images. A copy of the written consent is available for review by the Editor-in-Chief of this journal.

\section{Conflict of interest statement}

The authors declare that they have no conflict of interests and no financial support was received for this study.

\section{Authors' contributions}

All authors made contributions toward the conception and design of the research, acquisition of data and drafting of the manuscript. The final manuscript was read and approved by all the authors.

\section{References}

1. Campanacci M, Baldini N, Boriani S, Sudanese A. Giant-cell tumor of bone. J Bone Joint Surg [Am]. 1987;69(1):106-14.

2. Schajowicz F. Histological typing of bone tumours. Berlin: Spinger-Verlag; 1993.

3. Siebenrock KA, Unni KK, Rock MG. Giant-cell tumour of bone metastasising to the lungs: a long-term follow-up. J Bone Joint Surg Br. 1998;80:43-47.

4. Klenke FM, Wenger DE, Inwards CY, Rose PS, Sim FH. Giant cell tumor of bone. Clin Orthop Relat Res. 2011;469:591-99.

5. Unni KK. How to diagnose malignant giant cell tumor. Pathology Case Reviews. 6:33-37.

6. Szendroi M. Giant-cell tumour of bone. J Bone Joint Surg [Br]. 2004;86(1):5-12.

7. Ferreira N, Marais LC. Primary malignant giant cell tumour of the proximal tibia: a case report. I Cancer Res Ther. 2013;1(6):174-77.

8. Hoch B, Inwards C, Sundaram M, Rosenberg AE. Multicentric giant cell tumor of bone. Clinicopathologic analysis of thirty cases. J Bone Joint Surg Am. 2006;88(9):1998-2008.

9. Muscolo DL, Ayerza MA, Aponte-Tinao LA. Giant cell tumours of bone. Curr Orthop. 2001;15:41-50.

10. Schutte HE, Taconis WK. Giant cell tumor in children and adolescents. Skeletal radiol. 1993;22(3):173-76.

11. Puri A, Agarwal MG, Shah M, Jambhekar NA, Anchan C, Behle S. Giant cell tumor of bone in children and adolescents. J Pediatr Orthop. 2007;27(6):635-39.

12. Kransdorf MJ, Sweet DE, Buetow PC, Giudici MA, Moser RP, Jr. Giant cell tumor in skeletally immature patients. Radiology. 1992;184(1):233-37.

13. Picci P, Manfrini M, Zucchi V, Gherlinzoni F, Rock M, Bertoni $\mathrm{F}$, et al. Giant-cell tumor of bone in skeletally immature patients. J Bone Joint Surg [Am]. 1983;65(4):486-90.

14. Morgan JD, Eady JL. Giant cell tumor and the skeletally immature patient. J South Orthop Assoc. 1999;8(4):275-84.

15. Hoeffel JC, Galloy MA, Grignon Y, Chastagner P, Floquet J, Mainard L, Kadiri R. Giant cell tumor of bone in children and adolescents. Rev Rhum Engl Ed. 1996;63(9):618-23.

16. Sait A, Nithyanath M, VM C. Giant cell tumour of the distal humerus treated with elbow arthroplasty: A case report. Int J Case Rep Images. 2012;3(4):37-40.

17. Zahid M, Asif N, Sabir AB, Siddiqui YS, Julfiqar M. Metachronous multicentric giant cell tumour of the upper extremity in a skeletally immature girl: A rare presentation. Acta Orthop Belg. 2010;76(5):694-98.

18. Jaffe HL. Giant-cell tumour (osteoclastoma) of bone: its pathologic delimitation and the inherent clinical implications. Ann R Coll Surg Engl. 1953;13(6):343-55.

19. Aoki J, Tanikawa H, Ishii K, Seo GS, Karakida O, Sone S, Ichikawa T, Kachi K. MR findings indicative of hemosiderin in giant-cell tumor of bone: frequency, cause, and diagnostic significance. AJR Am J Roentgenol. 1996;166(1):145-48.

20. Lim YW, Tan MH. Treatment of benign giant cell tumours of bone in Singapore. Ann Acad Med Singapore. 2005;34(3): 235-37.

21. Moon MS, Kim SS, Moon JL, Kim SS, Moon H. Treating giant cell tumours with curettage, electrocautery, burring, phenol irrigation, and cementation. J Orthop Surg. 2013;21(2):209-12.

This article is also available online on the SAOA website (www.saoa.org.za) and the SciELO website (www.scielo.org.za). Follow the directions on the Contents page of this journal to access it. 